\title{
Risk Analysis and Antibiogram Spectrum of Escherichia coli 0157: H7 Serotype from Children Stool and Raw Bovine Meat in Households Across Cross River State, Nigeria
}

\author{
Nfongeh Joseph Fuh ${ }^{1, ~ *}$, Owoseni Mojisola Christiana ${ }^{1}$, Obande Godwin Attah ${ }^{1}$, Upla Peter Uteh ${ }^{1}$, \\ Odonye Dauda Dantani ${ }^{1}$, Fadayomi Victor Kolawole ${ }^{1}$, Uchenwa Mercy Ogechi ${ }^{2}$ \\ ${ }^{1}$ Department of Microbiology, Faculty of Science, Federal University Lafia, Lafia, Nigeria \\ ${ }^{2}$ Department of Microbiology, Faculty of Biological Sciences, University of Calabar, Calabar, Nigeria
}

Email address:

dejoeman@yahoo.com (N. J. Fuh)

${ }^{*}$ Corresponding author

\section{To cite this article:}

Nfongeh Joseph Fuh, Owoseni Mojisola Christiana, Obande Godwin Attah, Upla Peter Uteh, Odonye Dauda Dantani, Fadayomi Victor Kolawole, Uchenwa Mercy Ogechi. Risk Analysis and Antibiogram Spectrum of Escherichia coli O157: H7 Serotype from Children Stool and Raw Bovine Meat in Households Across Cross River State, Nigeria. European Journal of Clinical and Biomedical Sciences. Vol. 4, No. 3, 2018, pp. 39-45. doi: 10.11648/j.ejcbs.20180403.11

Received: June 9, 2018; Accepted: July 24, 2018; Published: August 24, 2018

\begin{abstract}
This cross sectional study is aimed at evaluating the risk factors and antibiogram profiles of Escherichia coli O157:H7 in children stool and bovine meat obtained from selected households across Cross River State, Southern Nigeria. A total of 360 samples of fresh household bovine meat and 366 children diarrheal and nondiarrheal stool samples each were collected and examined for E. coli O157: H7 using standard culture and serological methods. Confirmed E. coli O157: H7 isolates were evaluated for antimicrobial susceptibility using the Agar disc diffusion method. The total positive samples for $E$. coli O157: H7 in household meat was 76/360 (21.11\%,) while the diarrheaic and nondiarrheaic stool samples had 70/366 $(19.13 \%)$ and $5 / 366(1.37 \%)$ positive samples respectively. A significant difference was observed in the prevalence values among the bovine meat samples from various households and between the diarrheaic and nondiarrheaic samples at $\mathrm{p}<0.05$. Risk factors such as Age range with highest prevalence value at 1-2yrs (26.83\%); Occupation of parent/guardian with highest value from farming $(25.67 \%)$ and Main domestic water source with highest value from surface water $(28.21 \%)$ were observed to significantly affect the prevalence of the pathogen in children diarrheaic stool $(\mathrm{p}<0.05)$. All 70 diarrheaic isolates were resistant to one or multiple antibiotics with highest values obtained from tetracycline (88.6\%) and cotrimoxazole (77.1\%). This study revealed that bovine meat and some human and environmental factors play a vital role in the establishment of $E$. coli O157:H7 infection in children in the study communities with diarrheal stool being the main vehicle for secondary infections in humans. Cattle therefore serve as a major source of transmission of multi drug resistant $E$. coli $\mathrm{O} 157: \mathrm{H} 7$ to humans hence the need for continuous surveillance of this pathogen and implementation of legislation against indiscriminate use of antibiotics in diary farms.
\end{abstract}

Keywords: Escherichia coli O157:H7, Children Stool, Bovine Meat, Risk Factors, Antibiotics, Nigeria

\section{Introduction}

Shiga toxin-producing Escherichia coli (STEC) are not only responsible for foodborne poisoning that induced diarrhea and hemorrhagic colitis but also for more severe syndromes in humans such as hemolytic uremic syndrome that can cause death $[1,2]$. It is a zoonotic agent whose main reservoirs are cattle and other ruminants [3]. Harbouring of E. coli $\mathrm{O} 157$ in cattle is a significant concern for public health because of their transmitting capability to humans through contaminated foods and water with faeces from cattle $[4,5]$. [6] reported that infection of cattle which are 
major food animal in Nigeria with VTEC O157 portends an epidemiological causal association to infection in humans.

Outbreaks of STEC infections involving serogroup O157 have been reported from different countries of the world including United States, Canada, Asia, Australia, Europe, and Africa through various sources of infections and different case fatalities [7]. Children in developing countries have been reported to be more vulnerable to diarrhoeagenic $E$. coli infections especially those between six months and two years of age. [8]. A number of outbreaks among children have been attributed to the consumption of raw milk and dairy products [9]. Food borne diseases are common in developing countries, including Nigeria, because of the prevailing poor food handling and sanitation practices, inadequate food safety laws, weak regulatory systems, lack of financial resources to invest in safer equipment, and lack of education for food-handlers.

Although antibiotic use in STEC infections is controversial because of the potential to increase production and secretion of Shiga toxins, yet recent reports indicate that antimicrobial resistance of $E$. coli $\mathrm{O} 157$ is on the rise $[3,10,11,12,13]$. Apart from the therapeutic use of antimicrobials in human and veterinary medicine, they are routinely used for disease prevention and growth promotion in animal production. This practice leads to the inevitable selection of antimicrobial resistance among commensals in the intestinal tracts of food animals, which poses a public health threat. Food animals, in particular mature cattle, which may be asymptomatic carriers of $E$. coli $\mathrm{O} 157: \mathrm{H} 7$ when exposed to antimicrobial agents in the animal production environment, may serve as a reservoir of antimicrobial-resistant bacteria [14].

The studies of antimicrobials susceptibility of $E$. coli O157:H7 may have more therapeutic significance as recent studies have indicated a possible role of early administration of antimicrobials in preventing the progression of haemolytic uremic syndrome and haemorrhagic colitis both caused by $E$. coli $\mathrm{O} 157: \mathrm{H7}$ [15]. This study was therefore carried out to determine the risk factors and antibiogram of $E$. coli O157:H7 from humans and animal sources in some communities in Cross River State, Nigeria.

\section{Method}

\subsection{Study Area}

This study was carried out in selected highly populated communities in Cross River State, Nigeria where. cattle rearing is prominent, involving migrants from the northern parts of the country and whose grazing areas are usually unrestricted

The study area was mapped out according to political senatorial districts i.e Northern, Central and Southern Districts. Each senatorial district was further mapped out into two sampling areas (SA) each comprising of two most populated Local Government Areas (LGAs) namely SA1 (Obudu/Bekwarra LGAs), SA2 (Ogoja/Yala LGAs), SA3 (Ikom/Boki LGAs), SA4 (Obubra/Yakurr LGAs), SA5
(Akamkpa/Biase LGAs) and SA6 (Calabar Municipality/Akpabio LGAs). The choice of the sampling areas was based on the population, presence of abattoirs, cattle pens, livestock activities and healthcare facilities. The Sampling which was restricted to households was done monthly between June, 2011 and February, 2012

\subsection{Collection of Meat Samples}

A total of 60 fresh meat samples were collected from households within each sampling area. About $50 \mathrm{~g}$ portion of each sample was cut off from the stock using a sterile knife and forceps, wrapped in aluminium foil and placed in a sterile polyethene bag. All samples were transported in ice cold box $\left(4^{\circ} \mathrm{C}\right)$ to the laboratory for microbiological analysis within $24 \mathrm{hrs}$.

\subsection{Collection of Stool Samples}

Stool samples were obtained from children age between 0 5 years that had not been on any antibiotic treatment for at least $48 \mathrm{hrs}$ prior to sample collection. A total of 366 diarrhoeic and nondiarrhoeaic stool samples each were collected from both out-patients and in-patients in paediatric wards and those on post-natal visits in hospitals located in the sampling areas, after obtaining ethical clearance. A case of diarrhoea was defined as a history of three or more stools of loose consistency during the previous 24 hours [39] Parents/guardians were asked for and provided informed consent for participation of their wards in this study. Questionnaires were also distributed to them to provide some anthropogenic and environmental information relating to the subjects. Samples were collected in clean, leak-proof screwcapped plastic containers containing Amies transport medium. Rectal swabs immersed in the transport medium were also collected in cases where stool samples were unavailable. All samples collected were transported within $24 \mathrm{hrs}$ in an ice cold box at $4^{\circ} \mathrm{C}$ to the Microbiology Laboratory, University of Calabar for analysis.

\subsection{Enrichment of Samples}

About $1.0 \mathrm{ml}$ of each faecal sample suspension from transport medium was introduced into $10 \mathrm{ml}$ of buffered peptone water containing cefixime $(0.05 \mathrm{mg} / \mathrm{l})$ and vancomycin $(8.0 \mathrm{mg} / \mathrm{l})$ (BPW-CV) and vigorously vortexed for 30 s to homogenize the mixture. It was then incubated at $37^{\circ} \mathrm{C}$ for $24 \mathrm{hrs}$ for enrichment.

For the bovine meat samples, about $10 \mathrm{~g}$ of each sample was homogenized in $90 \mathrm{ml}$ of phosphate buffered saline containing cefixime $(0.05 \mathrm{mg} / \mathrm{l})$ and vancomycin $(8.0 \mathrm{mg} / \mathrm{l})$ by blending for $1 \mathrm{~min}$ using a Q-link blender (QL-2L40). The resultant slurry was also incubated at $37^{\circ} \mathrm{C}$ for $24 \mathrm{hrs}$.

\subsection{Presumptive Identification of E. coli 0157 Antigens in Enriched Samples}

The Diagnostic Automation Enzyme-linked Immunosorbent Assay (ELISA) technique comprising of anti-E. coli $\mathrm{O} 157$ antibodies impregnated in the wells was 
used for the qualitative detection of E. coli $\mathrm{O} 157$ antigens in all the enriched samples [16].

\subsection{Isolation of E. coli O157: H7}

All enriched samples with positive ELISA results were analysed using the standard E. coli O157: H7 culture technique as recommended by [3]. The samples were serially diluted to $10^{-3}$ using physiological saline $(0.85 \% \mathrm{w} / \mathrm{v} \mathrm{NaCl})$ and spread plated on sorbitol MacConkey agar supplemented with cefixime $(0.5 \mathrm{mg} / \mathrm{l})$ and potassium tellurite $(2.5 \mathrm{mg} / \mathrm{l})$ (SMAC-CT) and incubated at $42^{\circ} \mathrm{C}$ for $24 \mathrm{hrs}$. Colourless sorbitol-negative colonies were picked as presumptive identification of E. coli $\mathrm{O} 157: \mathrm{H} 7$ isolates. Growths on 4Methylumbilliferyl- $\beta$-D-Glucoronide (MUG) broth and fluorescence of the broth under uv light at $650 \mathrm{~nm}$ wavelength was used as a confirmatory test. Also, H7 serotyping using standard E. coli O157: H7 antisera (Difco Laboratories, Detroit, Mich.) and other biochemical tests typical to E. coli were used as confirmatory tests. The data were analysed with SPSS version 11.0 software (SPSS Inc, Chicago, Il).

\subsection{Determination of Antibiotic Susceptibility}

All E. coli O157: $\mathrm{H} 7$ isolates were tested for antimicrobial susceptibility by the agar disk diffusion technique in accordance to Clinical and Laboratory Standards Institute (CLSI) criteria using 11 antibiotics with the following content: Amoxicillin $(48 \mu \mathrm{g})$, Ampicillin $(32 \mu \mathrm{g})$, Ceftriaxone $(64 \mu \mathrm{g})$, Gentamicin $(16 \mu \mathrm{g})$, Cotrimoxazole $(25 \mu \mathrm{g})$, Tetracycline $(30 \mu \mathrm{g})$, Cefuroxime $(32 \mu \mathrm{g})$, Ofloxacin $(16 \mu \mathrm{g})$,

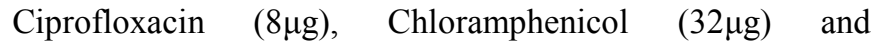

Nitrofurantoin $(32 \mu \mathrm{g})$. Results were interpreted using the CLSI criteria [17].

\section{Results}

A comparison of the prevalence of E. coli $\mathrm{O} 157: \mathrm{H} 7$ in household bovine meat, diarrhoeal and nondiarrhoeal stool samples is shown in Figure 1. Highest overall prevalence of $21.11 \%$ was obtained from the bovine meat while the diarrhoeal stool samples had $19.13 \%$. Nondiarrhoeal samples had the least overall value of $1.37 \%$. However, the percentage prevalence of the pathogen in the household bovine meat and diarrhoeal samples from the various sampled areas had no significant difference $(\mathrm{p}>0.05)$

Results of the impact of some anthropogenic and environmental factors on the prevalence of E. coli $\mathrm{O} 157: \mathrm{H} 7$ in children diarrhoeal stool are presented in table 1. Factors such as age range, Occupation of parent/guardian and main domestic water source significantly influenced the prevalence of the pathogen.

Results for the antibiotics resistant profiles of E. coli O157: H7 isolates from household bovine meat and children diarrhoeal stool on some commonly used dairy farm antibiotics are shown in Table 2. Out of the 76 bovine meat isolates tested, were resistant to tetracycline, cotrimoxazole, and ampicillin. The highest resistance of 62 (88.6\%) out of the 70 diarrhoeal isolates tested was obtained with tetracycline followed by cotrimoxazole and ampicillin with $54(77.1 \%)$ and $47(67.2 \%)$ respectively.

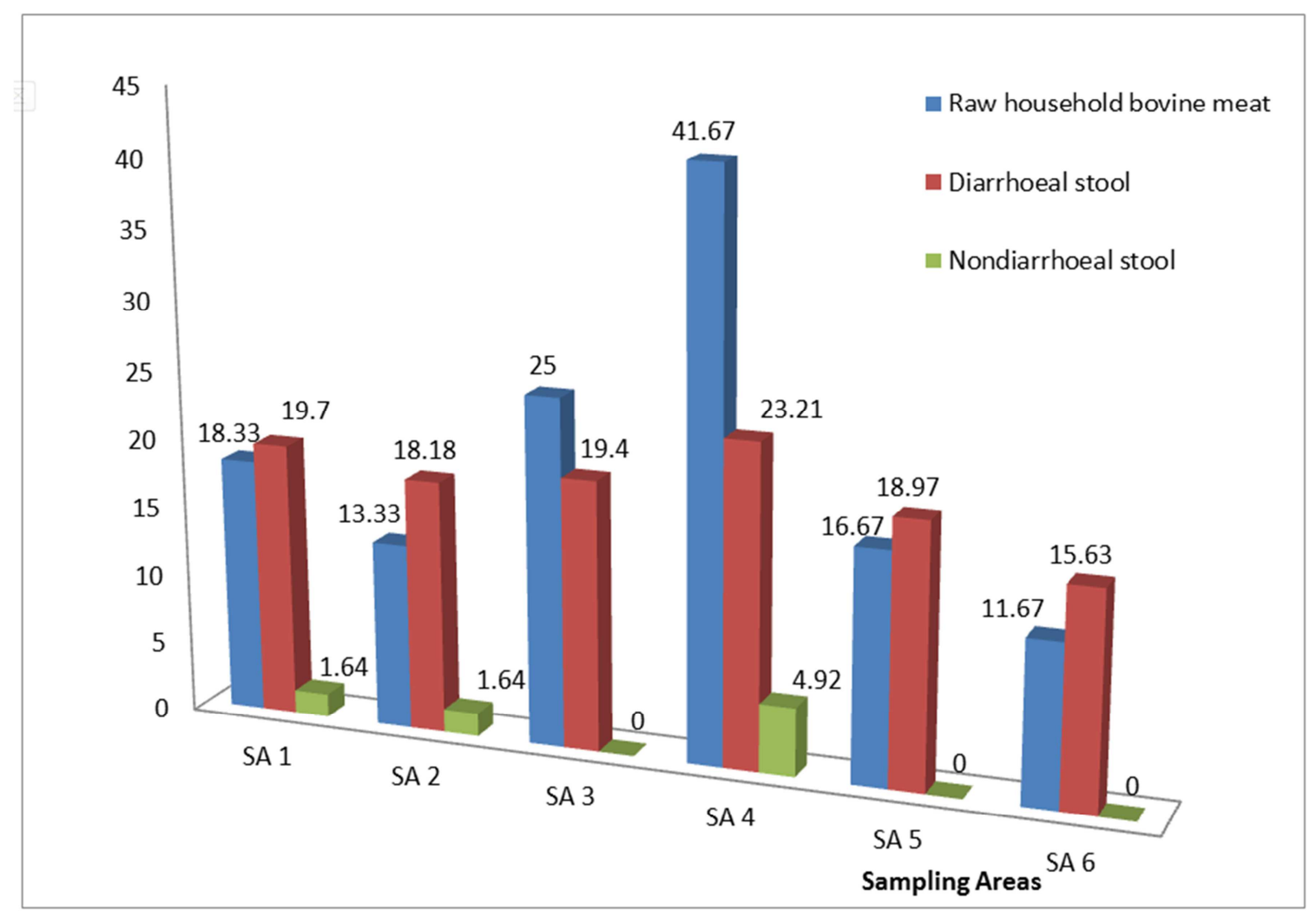

Figure 1. Percentage prevalence of Escherichia coli 0157:H7 in raw household bovine meat, diarrhoeal and nondiarrhoeal stool in the various study areas. 
Table 1. Relative prevalence of Escherichia coli 0157:H7 in diarrheaic samples based on some anthropogenic and environmental factors.

\begin{tabular}{|c|c|c|c|c|c|c|c|}
\hline \multirow{2}{*}{ Risk factors } & SA1 & SA2 & SA3 & SA4 & SA5 & SA6 & Total Freq \\
\hline & n/N(\%) & $\mathbf{n} / \mathbf{N}(\%)$ & $\mathbf{n} / \mathbf{N}(\%)$ & n/N(\%) & n/N(\%) & n/N(\%) & $\mathrm{n} / \mathrm{N}(\%)$ \\
\hline \multicolumn{8}{|l|}{ Age } \\
\hline \multicolumn{8}{|l|}{$\begin{array}{l}\text { Range } \\
\text { (yrs) }\end{array}$} \\
\hline$<1$ & $5 / 27(18.52)$ & $4 / 20(20.00)$ & $4 / 24(8.33)$ & $6 / 25(24.00)$ & $3 / 2(14.29)$ & $2 / 26(7.70)$ & $24 / 143(16.78)$ \\
\hline $1-2$ & $1 / 8(12.50)$ & $2 / 6(33.33)$ & $2 / 9(22.22)$ & $1 / 4(25.00)$ & $3 / 7(42.86)$ & $2 / 7(28.57)$ & $11 / 41(26.83)$ \\
\hline $3-4$ & $3 / 13(23.08)$ & $2 / 9(22.22)$ & $2 / 14(14.29)$ & $3 / 10(30.00)$ & $3 / 11(27.27)$ & $2 / 10(20.00)$ & $15 / 67(22.39)$ \\
\hline 5 & $4 / 18(22.22)$ & $2 / 20(10.00)$ & $5 / 20(25.00)$ & $3 / 17(17.65)$ & $2 / 19(10.53)$ & $4 / 21(19.05)$ & $\begin{array}{l}20 / 115(17.39) \\
p<0.05\end{array}$ \\
\hline \multicolumn{8}{|l|}{ Gender } \\
\hline Male & $8 / 35(22.86)$ & $4 / 25(16.00)$ & $6 / 31(19.35)$ & $8 / 29(27.59)$ & $4 / 26(15.38)$ & 6/33(26.09) & $36 / 179(20.11)$ \\
\hline Female & $5 / 31(16.13)$ & $6 / 30(20.00)$ & $7 / 36(19.44)$ & $5 / 27(18.52)$ & $7 / 32(21.88)$ & $4 / 31(12.90)$ & $\begin{array}{l}34 / 187(18.18) \\
p>0.05\end{array}$ \\
\hline \multicolumn{8}{|c|}{ Occupation of Parent/Guardian } \\
\hline CSV & $1 / 10(10.00)$ & $0 / 6(0.00)$ & $0 / 9(0.00)$ & $0 / 4(0.00)$ & $1 / 6(16.67)$ & $0 / 9(0.00)$ & $2 / 44(4.55)$ \\
\hline BSN & 2/17(11.76) & $3 / 9(33.33)$ & $1 / 19(5.26)$ & $3 / 13(23.08)$ & $2 / 12(16.67)$ & 2/18(11.11) & $13 / 88(14.77)$ \\
\hline ATN & $4 / 20(20.00)$ & $2 / 21(9.52)$ & $7 / 18(38.87)$ & $4 / 20(20.00)$ & $3 / 17(17.65)$ & $4 / 17(23.53)$ & $24 / 113(21.24)$ \\
\hline FRM & $6 / 19(31.58)$ & $5 / 19(36.32)$ & $5 / 21(23.81)$ & $6 / 19(31.58)$ & $5 / 23(21.74)$ & $4 / 20(20.00)$ & $\begin{array}{l}31 / 121(25.62) \\
\mathrm{p}<0.05\end{array}$ \\
\hline \multicolumn{8}{|c|}{ Main Domestic water source } \\
\hline Well & $2 / 8(25.00)$ & $1 / 7(14.29)$ & $2 / 10(20.00)$ & $3 / 9(33.33)$ & 2/11(18.18) & $3 / 10(30.00)$ & $13 / 55(23.64)$ \\
\hline $\mathrm{BHL}$ & $6 / 35(17.14)$ & $5 / 32(15.63)$ & $5 / 31(16.13)$ & $3 / 29(10.34)$ & $4 / 21(19.05)$ & $5 / 37(13.51)$ & $13 / 88(15.14)$ \\
\hline Tap & $1 / 7(14.29)$ & $2 / 10(20.00)$ & $2 / 9(22.22)$ & $1 / 6(16.67)$ & $0 / 4(0.00)$ & $1 / 12(8.33)$ & $7 / 48(14.58)$ \\
\hline SWT & $4 / 16(25.00)$ & 2/6(33.33) & $4 / 17(23.53)$ & $6 / 12(50.00)$ & $5 / 22(22.73)$ & $1 / 5(20.00)$ & $\begin{array}{l}22 / 78(28.21) \\
p<0.05\end{array}$ \\
\hline
\end{tabular}

$\mathrm{CSV}=$ Civil servant; $\mathrm{BSN}=$ Business ATN $=$ Artisan; FRM $=$ Farmer; BHL $=$ Borehole; SWT $=$ Surface water.

Table 2. Antibiotics susceptibility profile of E. coli O157:H7 isolates from raw household bovine meat and children diarrhoeal samples on some commonly used dairy farm antibiotics.

\begin{tabular}{|c|c|c|c|c|c|c|}
\hline \multirow{5}{*}{ Antibiotic. $(\mu \mathrm{g})$} & \multicolumn{6}{|c|}{ Susceptibility } \\
\hline & \multicolumn{2}{|c|}{$\mathbf{R}$} & \multicolumn{2}{|l|}{ I } & \multicolumn{2}{|l|}{$\mathbf{S}$} \\
\hline & BMI & CDI & BMI & CDI & BMI & CDI \\
\hline & $N=76$ & $\mathrm{~N}=\mathbf{7 0}$ & $N=76$ & $\mathrm{~N}=\mathbf{7 0}$ & $N=76$ & $\mathrm{~N}=\mathbf{7 0}$ \\
\hline & No. $(\%)$ & No $(\%)$ & No $(\%)$ & No. $(\%)$ & No $(\%)$ & No. $(\%)$ \\
\hline AMP (32) & $71(93.42)$ & $47(67.14)$ & $6(5.60)$ & $8(11.43)$ & $30(28.01)$ & $15(21.43)$ \\
\hline $\operatorname{AMX}(48)$ & $36(33.61)$ & $39(55.71)$ & $14(13.10)$ & $10(14.29)$ & $57(53.30)$ & $21(30.00)$ \\
\hline $\mathrm{CEF}(32)$ & $12(11.23)$ & $16(22.86)$ & $17(15.9)$ & $13(18.57)$ & $78(72.88)$ & $41(58.57)$ \\
\hline CLM (32) & $36(33.61)$ & $31(44.29)$ & $11(10.26)$ & $9(12.86)$ & $60(56.1)$ & $30(42.86)$ \\
\hline $\operatorname{COT}(25)$ & $83(77.58)$ & $54(77.14)$ & $3(2.81)$ & $4(5.71)$ & $21(19.57)$ & $12(17.14)$ \\
\hline $\mathrm{CPF}(08)$ & $24(22.40)$ & $8(11.43)$ & $8(4.52)$ & $13(18.57)$ & $75(70.10)$ & $49(70.00)$ \\
\hline GEN (16) & $48(44.88)$ & $39(55.71)$ & $11(10.21)$ & $7(10.00)$ & $48(44.91)$ & $24(34.29)$ \\
\hline $\operatorname{NTF}(23)$ & $48(44.90)$ & $23(32.86)$ & $14(13.14)$ & $11(15.71)$ & $46(43.02)$ & $36(51.43)$ \\
\hline OFX (16) & $36(33.63)$ & $16(22.85)$ & $9(8.43)$ & $9(12.86)$ & $62(58.01)$ & $45(64.29)$ \\
\hline TET(30) & $83(77.64)$ & $62(88.57)$ & $5(4.74)$ & $1(1.43)$ & $19(17.66)$ & $7(10.00)$ \\
\hline
\end{tabular}

AMP, Ampicillin; AMX, Amoxicillin; CEF, Cefurantoin; CFT, Ceftriazone; CLM, Chloramphenicol; COT, Cotrimoxazole; CPF, Ciprofloxacin; GEN, Gentamicine; NTF, Nitrofurantoin; OFX, Ofloxacin; TET, Tetracycline, N= Total number of test isolates; BMI=Bovine meat isolates; CDI= Children diarrhoeal isolates; $\mathrm{R}=$ Resistant isolates; $\mathrm{I}=$ Intermediate resistant isolates; $\mathrm{S}=$ Sensitive isolates.

\section{Discussion}

In the present study, E. coli $\mathrm{O} 157: \mathrm{H} 7$ was isolated from bovine meat from selected households in Calabar, Southern Nigeria. The overall prevalence of E. coli $\mathrm{O} 157: \mathrm{H} 7$ from bovine meat in the present study $(21.11 \%)$ was higher than the $4.2 \%$ reported by [18] and $10.2 \%$ by [19] in various areas in Ethiopia. In contrast, the results obtained in this study was higher than the $8.8 \%$ prevalence reported by [20] in South Africa and [21] in Iran; and lower than $53 \%$ prevalence as reported by [22] in fresh beef meat in Nigeria. The presence of
E. coli $\mathrm{O} 157: \mathrm{H} 7$ in meat might be due to contamination either from gastrointestinal content and/or skin [23]. This prevalence (contamination) rate could be due to the hygienic practices, cooling and storage time used. Moreover there could be risk of carcass contamination and cross and subsequent contamination, during transportation, environment, handling of meat at households. More so, the fact that bovine has been implicated as the principal reservoir of this pathogen as compared with other food animals is also of immense concern.

Diarrhoeal diseases are one of the major health problems in the world. Every year more than two million deaths from 
diarrhoea in children under five in developing countries occur [24]. The $19.13 \%$ prevalence of E. coli O157: H7 among diarroeal children (0-5years) obtained in this study is higher than $1.39 \%$ and the $6 \%$ prevalence reported by [25] and [26] in Kaduna and Lagos, Nigeria but lower than the $20 \%$ prevalence recorded by [27] in Benin, Nigeria. Although there are differences in prevalence rate of E. coli O157: $\mathrm{H} 7$ in the stool samples in different parts of Nigeria, this result however shows that $E$. coli O157: $\mathrm{H} 7$ remains an aetiological agent for diarrhoea in Nigeria. The presence of E. coli O157: $\mathrm{H} 7$ in stool samples might not be unconnected to the fact that patients have been exposed to unsanitary conditions such as consumption of contaminated water, food, fruits and vegetables.

The findings in this study indicates that age remains a major risk factor in diarrhoea disease. Children between the ages of $0-5$ are highly vulnerable to diarrhoea as this study has shown. The high occurrence rate $E$. coli $\mathrm{O} 157: \mathrm{H} 7$ among diarrhoeal children 0-5 years in this study may be due to the fact that children within this age group on their own cannot differentiate between what to eat and what not to eat; they have not learnt the rudiment of adherence to aseptic or hygienic practices. Also, their weaker immunity as a result of them having lost their inborn immunity after being weaned from breast milk. Young children use more water over the course of a day given their higher metabolic rates, also their kidneys are less able to conserve water compared to older children and adults as such diarrhoea is usually prevalent and often life threatening too once caused by this pathogen.

Also, this study has revealed that 5 persons $(1.37 \%)$, although not having diarrhoea, had E. coli $\mathrm{O} 157: \mathrm{H} 7$ isolated from their stool specimens. According to [28] and [29] healthy carriage of enteric pathogens in general and diarrhoegenic E.coli in particular is high in many African studies. It is not surprising, therefore, to isolate this organism from apparently healthy individuals, as human infection caused by E. coli $\mathrm{O} 157: \mathrm{H} 7$ can present a broad clinical spectrum ranging from asymptomatic cases to death [30]. Since asymptomatic cases can occur in outbreaks, there has been concern that persons with such infections could unwittingly spread infection to others. The existence of such asymptomatic cases during outbreaks has been well documented [29]. Asymptomatic infections have also been demonstrated in family members and other close contacts of persons with hemolytic uremic syndrome or symptomatic $E$. coli O157:H7 [31].

The results obtained from this study showed that all the $E$. coli O157: $\mathrm{H} 7$ isolates were resistant to all antibiotics at different degrees. The development of antimicrobial resistance by the bacteria to these drugs poses a major challenge in both human and animal medicine because these drugs are commonly used in the treatment of human patients and in veterinary practice. Uncontrolled usage of antibiotics in treatment of animals and their incorporation in animal feeds has been suspected to account significantly to the increase in antibiotic resistance in human bacterial isolates. $[32,33]$

Resistance to Ampicillin (a Beta-lactam) and tetracycline were the highest among isolates from bovine meat. This is in agreement with the finding of [34], which recorded a high level of tetracycline and ampicillin resistance of $91.4 \%$ and $70.0 \%$ among isolates of E. coli $\mathrm{O} 157: \mathrm{H} 7$. [35] also observed high resistance to tetracycline $(81.4 \%)$. The high level of resistance of tetracycline and ampicillin obtained in this study may be as a result of it being the most commonly available antibiotic used as growth promoter and routine chemoprophylaxis among livestock [34]. Moreover, tetracycline often used abusively in livestock feed in many countries, resulting in the emergence of resistance among workers (farmers, slaughterers of animals) and consumers of meat and milk. This has led some countries, like the United Kingdom, to prohibit the utilization of this antibiotic in livestock feed [36]. Furthermore, isolates from humans exhibited highest degree of resistance to both tetracycline and ampicillin. [37] reported similarly high $(100.0 \%$ and $94.0 \%)$ trend of resistance of E. coli $\mathrm{O} 157: \mathrm{H} 7$ to tetracycline and ampicillin in humans. In most developing countries, people with gastrointestinal infections readily purchase it across the counter for self-medication. According to [28] these antibiotics are known to be extensively used in developing countries.

High degree of resistance to quinolone (Ofloxacin) is alarming since they are known to be very potent antimicrobial agents. It could probably be due to excessive usage of the drugs (for both human and veterinary purposes), inappropriate prescription or substandard drugs administration. However some workers have also reported resistance to the quinolones in Nigeria $[38,39]$ as well as in other countries [40]. Nevertheless, the relatively lower resistance recorded to Ciprofloxacin (fluoroquinolone) shows that this class of antibiotic can be used as antibiotic of choice against E. coli O157:H7 infections. Prior to their use, resistance was rare. A previous assessment of some six antibiotics against clinical isolates of $E$. coli showed them to be the most efficacious [40]. Also, [] demonstrated lower resistance to flouroquinolone drugs in E. coli $0157: \mathrm{H7}$ isolated from humans, cattle, swine, and food sources.

The lower resistance of the isolates to gentamicin (an aminoglycoside) could be attributed to its requirement for parenteral administration which hinder their misuse and abuse due the discomfort associated with injections. This finding agrees with that of [42] who reported that none of the E. coli $\mathrm{O} 157: \mathrm{H} 7$ isolates tested was resistant to gentamicin. The widespread and inappropriate use of antibiotics is a significant contributing factor to the development and spread of bacterial resistance to antimicrobial agents [43]. For most bacteria, there is evidence that increased usage of a particular antimicrobial correlates with increased levels of bacterial resistance [44]. Similarly, [37] and [45] reported lower instances of E. coli $\mathrm{O} 157: \mathrm{H} 7$ susceptibility to gentamicin. Contrarily, [46] reported $100 \%$ susceptibility to gentamicin in Bangladesh. Also, [47] reported that most of the STEC strains were sensitive to gentamicin.

Isolates were less resistant to nitrofurantoin and ceftriazone in this study. Similar studies by [48] and [49] in Ethiopia and [50] in Nigeria have reported comparable susceptibility rates. High resistance to cotrimoxazole is in 
agreement with the finding of [13], who reported $66.7 \%$ resistance which further concurs to the report of [41]. This antimicrobial agent is commonly used to treat respiratory infections, diarrhoea, mastitis, and other infections in beef and dairy cattle which may be consumed by humans.

\section{Conclusion}

Contaminated bovine meat serve as a major route for the transmission of Escherichia coli O157:H7 which causes childhood diarrhoea This study also confirms the widespread resistance of this pathogen to most commonly used antimicrobial agents in both human and animal health practice in not just the study area. The public health significance of these findings is that antimicrobial resistant bacteria from food animals may colonize the human population via the food chain, contact through occupational exposure, or waste runoff from meat production facilities to the neighborhood. Indiscriminate and misuse of antimicrobials among livestock producers and marketers in Nigeria could also be responsible for the resistance pattern obtained in this study.

\section{References}

[1] Griffin, P. M. (1995). Escherichia coli O157:H7 and other Enterohemorrhagic Escherichia coli, P. 739-761. In M. J. Blaser, P. D. Smith, J. I. Rovin, H. B. Greenberg, And R. L. Guerrant (Ed.), Infections of the Gastrointestinal Tract. Raven Press, New York, NY

[2] Seibt, F., Filer, G., Gellermann, J., Beutin, L., Ehrih, J. (1995). The Heterogeneity of Haemolytic Uraemic Syndromes in Children and Adults. Nephrologisches Jahresgespräch. Editor: Deutsche Dialysegesellschaft.

[3] Mora, A., Blanco, J. E. and Blanco, M. (2005). Antimicrobial resistance of Shiga toxin (verotoxin)- producing Escherichia coli $\mathrm{O} 157: \mathrm{H} 7$ and non-O157 strains isolated from humans, cattle, sheep and food in Spain. Research in Microbiology, 156(7): 793-806.

[4] Mead, P. S. and Griffin, P. M. (1998). Escherichia coli O157:H7. Lancet, (35): 1207-1212.

[5] Cooley, M. (2007). Incidence and Tracking of Esherichia coli O157:H7 in a major produce production region in California. PLos ONE, 2(11): e1159.

[6] Enem, S. I. and Oboegbulem, S. I. (2015). Epidemiology of Verocytotoxigenic Escherichia coli (VTEC) O157 Serotype in Cattle in Federal Capital Territory, Abuja, Nigeria. Journal of Veterinary Medicine and Research, 2(3): 10-26.

[7] Duffy, G. (2006). Emerging pathogenic E. coli. In: Emerging Foodborne Pathogens, M. Yasmine and A. Martin, Eds. Pp. 253-272, CRC.

[8] Presterl, E., Zuick, R. H., Reichmann, S., Aichelburg, A., Winkler, S., Kremsner, P. G and Graninger, A(2003). Frequency and Virulence Properties of Diarrhoeagenic Escherichia coli in Children with Diarrhoea in Gabon. American Journal of Tropical Medicine and Hygiene. 69(4):406-410.
[9] Nigatu, D., Berhanu, S., Shimelis, M., Yimer, M., and Dinaol, B. (2017). Prevalence and Antimicrobial Susceptibility Pattern of $E$. coli $\mathrm{O} 157: \mathrm{H} 7$ Isolated from Traditionally Marketed Raw Cow Milk in and around Asosa Town, Western Ethiopia. Veterinary Medicine International, (7): 1-7.

[10] Galland J C. (2001). Prevalence, antibiotic susceptibility, and diversity of Escherichia coli $\mathrm{O} 157: \mathrm{H} 7$ isolates from a longitudinal study of beef cattle feedlots. Applied and Environmental Microbiology, 67(4):1619-1627.

[11] Raji, M. A., Minga, U. and Machangu, R. (2006). Current epidemiological status of enterohaemorrhagic Escherichia coli O157:H7 in Africa," Chinese Medical Journal, 119(3): 217-222

[12] Walsh, C., Duffy, G., O’Mahony, R., Fanning, S., Blair, I. S. and McDowell, D. A. (2006). Antimicrobial resistance in Irish isolates of verocytotoxigenic Escherichia coli (E. coli)-VTEC. International Journal of Food Microbiology, 109(3): 173-178.

[13] Reuben, C. R. and Gyar, S. D. (2015). Isolation and Antibiogram of Shiga Toxin-Producing Escherichia coli O157:H7 from Diarrhoeic HIV/AIDS Patients in Lafia, Central Nigeria. International Research Journal of Microbiology, 6(2): 020-026,

[14] Meng, J. and Doyle, M. P. (1998). Emerging and evolving microbial foodborne pathogens. Bulletin de L'Institut Pasteur, 96: $151-164$.

[15] Molbak, K., Mead, P. S. and Griffin, P. M. (2002). Antimicrobial Therapy in Patients with Escherichia coli O157:H7 Infection. Journal of American Medical Association, 288:1014-6.

[16] Nfongeh J. F; Epoke, J; Antai, E. E; Ikpeme, E. M; Etim, L. B; Akeh, M. and Ekpiken, S. E. (2014). The Effects of Escherichia coli 0157:H7 lipopolysaccharide (LPS) from human, cattle and poultry isolates on haematological parameters of neonatal albino rats. European Journal of Experimental Biology 4(1):538-542

[17] Clinical and Laboratory Standard Institute (CLSI) (2007). Performance Standards for Antimicrobial Susceptibility Testing. Seventeenth Informational Supplement. Approved Standard M100-S17: Wayne, PA.

[18] Hiko, A., Asrat, D. and Zewde, G. (2008). Occurrence of Escherichia coli $\mathrm{O} 157: \mathrm{H} 7$ in retail raw meat products in Ethiopia. J Infect Dev Ctries., 2(5):389-393

[19] Tizeta, B., Girma, Z., Genene, T., Aklilu, F. and Kaleab, Z. (2014). Escherichia coli O157:H7 in Raw Meat in Addis Ababa, Ethiopia: Prevalence at an Abattoir and Retailers and Antimicrobial Susceptibility. International Journal of Food Contamination, 1(4): 3-8

[20] Abong'O, B. O. (2008). Prevalence of Escherichia coli 0157:H7 in water, meat, meat products and vegetables sold in the Eastern Cape Province of South Africa and its impact on the diarrhoeic conditions of HIV/AIDS patients. $\mathrm{PhD}$ Thesis University of Port Hare, South Africa.

[21] Hajian, S., Rahim, E. \& Mommtaz, H., (2011). A 3-year study of $E$. coli $0157: \mathrm{H} 7$ in cattle, camel, sheep, goat, chicken and beef minced meat. International Conference on Food Engineering and Biotechmology. 9: 162-166

[22] Dahiru, M., Uraih, N., Enabulele, S. A. and Shamsudeen, U. (2008). Prevalence of Escherichia coli 0157:H7 in fresh and roasted beef in Kano City, Nigeria. Bayero J Pure Appl Sci., $1: 39-42$ 
[23] McEvoy, J. M., Sheridan, J. J. and McDowell, D. A. (2004). Major pathogens associated with the processing of beef. In: Collins JD (ed) Smulders FJM. Wageningen Academic Publishers, Safety Assurance during Food Processing, pp 5780 .

[24] Fard, A. H., Bokaeian, M. and Qureishi, M. E. (2008). Frequency of Escherichia coli O157: H7 in children with diarrhoea in Zahedan, Islamic Republic of Iran. East Mediterr Health J., 14:1022-27

[25] . Abdulaziz, H. O., Aminu, M. and Machido, D. A. (2016). Isolation and Characterisation of Esherichia coli $\mathrm{O} 157$ in Human Stool Samples from Parts of Kaduna Metropolis Nigeria. American Journal of Food Science and Technology, 4(5): $125-128$.

[26] Olorunshola, I. D., Smith, S. I. and Coker, A. O. (2000). Prevalence of Enterohaemorrhagic Escherichian coli in Patients with Diarrhoea in Lagos, Nigeria. Actapathologica, microbiologica, etimmunologica Scandinavica, 108(11):761763.

[27] Esumeh, F. I, Isibor, J. O., Egbagbe, I. D. S. (2011). Screening For Escherichia Coli O157:H7 In Diarrheic Patients In Benin City, Nigeria. Journal of Microbiology and Biotechnology Research, 1(4): 1-4.

[28] Opintan, J. A., Bishar, R. A., Newman, M. J and Okeke, I. N. (2010). Carriage of diarrheagenic Escherichia coli by older children and adults in Accra Ghana. Trans $R$ Soc Trop Med Hyg., 104(7): 504-506.

[29] Umolu, P. I., Omigie, O., Tatfeng, Y., Omorogbe, F. I., Aisabokhale, F. and Ugbodagah, O. P. (2006). Antimicrobial susceptibility and plasmid profiles of Escherichia coli isolates obtained from different human clinical specimens in Lagos Nigeria. American Journal of Science, 2(4): 70-76.

[30] Lim, J. Y., Yoon, J and Hovde, C. J. (2010). A brief overview of Escherichia coli O157:H7 and its plasmid O157. J. Microbiol. Biotechnol., 20 (1):5-14.

[31] Marsh, J., MacLeod, A. F., Hanson, M. F., Emmanuel, F. X. S, Frost, J. A and Thomas, A. A. (1992). A restaurant-associated outbreak of E coli O157infection. J. Publ. Health Med., 14: 78-83.

[32] WHO. (2000). Global Principles for the Containment of Antimicrobial Resistance in Animals Intended For Food; Report of WHO Consultation With The Participation Of Food and Agriculture Organization of The United Nation and the Office International Des Epizooties, Geneva Switzerland 5- 9 June 2000. Department of Communicable Disease Surveillance and Response.

[33] Galland, C. J., Hyatt, R. D., Crupper, S. S. and Acheson, W. D. (2001). Prevalence, Antibiotic Susceptibility, and Diversity of E. coli $\mathrm{O} 157: \mathrm{H} 7$ Isolates from a Longitudinal Study of Beef Cattle Feedlots. Journal of Applied and Environmental Microbiology, 67(4):1619-27.

[34] Olatoye, I. O. (2010). The Incidence and Antibiotics Susceptibility of Escherichia coli O157:H7 from Beef in Ibadan Municipal, Nigeria. African Journal of Biotechnology, 9(8): 1196-1199.

[35] AlHaj, N., Mariana, N. S., Raha, A. R. and Ishak, Z. (2007). Prevalence of Antibiotic Resistance Among Escherichia coli from Different Sources. Malaysia Research Journal of Pharmacology, 1(2): 44-49.
[36] Helali, A. (2002). Pharmacologie Fondamentale Et Clinique A L'usage Des Etudiants En Médecine, Santé Collection, ENAG/ Editions. Pp 183.

[37] Naik, J. and Desai, P. (2012). Detection of Enterohaemorrhagic Escherichia coli (E. coli O157:H7) and its Drug Resistance Pattern. Journal of Environmental Research and Development, 7(1): 51-55

[38] Daini, O. A., Ogbolu, O. D. and Ogunledun, A. (2005). Quinolones resistance and R- Plasmids of some Gramnegative enteric bacilli. African Journal of Clinical and Experimental Microbiology, 6(1): 14-20.

[39] Oteo, J., Lazaro, E., de Abjo, F. J., Baquero, F. and Campos, J. (2005). Spanish members of EARSS. Antimicrobial-resistant invasive Escherichia coli, Spain. Emerging Infectious Diseases, 11(4): 546- 553.

[40] Isibor, J. O., Erhunmwuns, P. I. and Nwobu, G. O. (2003). Antimicrobial susceptibility of clinical isolates of $E$. coli to six antimicrobial agents. Journal of Applied Basic Science, 1(2):37-40.

[41] Schroeder, C. M., Zhao, C., DebRoy, C., Torcolini, J., Zhao, S., White, D. G., Wagner, D. D., McDermott, P. F., Walker, R. D., and Meng, J. (2002). Antimicrobial Resistance of Escherichia coli O157 Isolated from Humans, Cattle, Swine, and Food. Appl. Environ. Microbiol. 68 (2): 576-581

[42] Reuben, C. R. and Owuna, G. (2013). Antimicrobial Resistance Patterns of Escherichia coli O157:H7 from Nigerian Fermented Milk Samples in Nasarawa State, Nigeria. Int. J. Pharmaceutical Sci. Invent., 2(3): 38-44.

[43] Mincey, B. A. and Parkulo, M. A. (2001). Antibiotic prescribing practices in a teaching clinic: comparison of resident and staff physicians. Southern Med. J., 94(4): $365-$ 369.

[44] Granizo, J. J., Aguilar, L., Casal, J., Dal-Re, R and Baquero, F. (2000). Streptococcus pyrogenes resistance to erythromycin in relation to macrolide consumption in Spain (1986-1997). $J$. Antimicrob. Chemother., 46: 959 - 964.

[45] Chandran, A. (2008). India Prevalence of Multiple Drug Resistant Escherichia coli Serotypes in a Tropical Estuary, India., Microb. Environ., 23( 2):153-158.

[46] Zinnha, M. A. (2008). Bangladesh, Drug sensitivity pattern of Escherichia coli isolated from samples of different Biological and environmental sources, Bangl. J. Vet. Med., 6(1): 13-18

[47] Chattopadhyay, U. K., Gupta, S. and Dutta, S. (2010). Search for shiga toxin producing Escherichia coli (STEC) including 0157: H7 strains in and around Kolkata., Ind. J. Med. Microbiol, 21(1), 17-20.

[48] Tesfaye, G., Astrat, D., Woldeamanuel, Y. and Gizaw, M. (2009). Microbiology of discharging ears in Ethiopia. Asian Pacific Journal of Tropical Medicine, 2(91): 60-67

[49] Abebe, M., Hailelule, A., Abrha, B., Nigus, A., Birhanu, M., Adane, H., Genene, T., Daniel, H., Getachew, G., Merga, G. and Haftay, A. (2014). Antibiogram of Escherichia coli strains from food of bovine origin in selected Woredas of Tigray, Ethiopia. Journal of Bacteriology Research, 6(3): 17-22.

[50] Wariso, B. A. and Ibe, S. N. (2006). Bacteriology of chronic discharging ears in Port Harcourt, Nigeria. West African Journal of Medicine, 25: 219-222. 